\title{
Smoking Cessation: Review Article
}

\section{Sarvath Ali*}

University of Cincinnati, USA

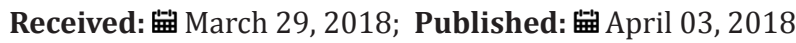

*Corresponding author: Sarvath Ali, University of Cincinnati, USA

\begin{abstract}
\section{Background}

Globally, including the United States, cigarette smoking is the single most important cause of premature death, even though it is preventable. The prevalence of smoking is high, although some resources have been dedicated to this problem. A variety of interventions have been tried on smoking prevention. From the public health perspective, it is the biggest concern. As there are numerous health benefits of smoking cessation, most individuals who smoke express a desire to quit. Studies show that most smokers in the United States and the United Kingdom report that they want to stop or intend to leave smoking at some point in life Hyland [1]. A multitude of non-pharmacological and pharmacological interventions now exist to aid smokers in cessation.
\end{abstract}

\section{Objectives}

To bring awareness among public and policy makers. To provide evidence and recommendations required for effective cessation interventions. To be carried out in public health globally.

\section{Methods}

Articles published from 2000 to 2016 were identified through electronic databases such as Medline, Pub Med, and EBSCO host.

\section{Conclusions}

This research paper suggests the trends of smoking habits and smoking cessation intervention strategies differ from region to region when viewed from an international perspective. This highlights the necessity for the improvement of new methods that prevent people from starting to smoke, motivate smokers to quit and enable them to sustain long-term cessation. Future research should examine whether increasing the rate of quit attempts would be key to improving the population smoking cessation rate.

Keywords: Smoking Prevention; Tobacco Use; Smoking Cessation; International.

\section{Introduction}

This article is a retrospective review of research articles on smoking cessation obtained through a search of selected databases from 1 Aug 2017 back to 31 Dec 2000. The purpose and goal of this report is to bring awareness to the population. Additionally, to provide data for professionals in public health and policymakers, to help make recommendations based on effective cessation intervention evidence. Also, to provide information to youth who indulge in tobacco smoking of the trends, prevalence, consequences

\section{Methods}

The articles published from 2000 to 2017 were identified retrospectively through electronic databases such as Medline, Pub Med, and EBSCO host. Peer review articles relevant to smoking cessation were chosen. Statistical information was gathered and further analyzed. Besides web-based resources, other important resources such as the Center for Disease Control (CDC) and the World Health Organization (WHO) were also utilized for research. and to inspire engaging in programs for smoking cessation. 


\section{Background}

Even though several preventive measures have been taken by the governments and several organizations, smoking remains a constant and severe problem in communities all over the world. Smoking-related diseases claim an estimated six million lives each year out of which 600,000 deaths were from exposure to second-hand smoke, though it is entirely preventable (WHO, 2014). An estimated 126 million Americans are regularly exposed to secondhand smoke each year National Institute on Drug Abuse [2]. More than 43 million adults are current smokers in the USA. Eightyeight percent of those adults who started smoking at their youth (age 11-12 years) almost became an addict when they turned 14 . Globally, as well as in the US, tobacco smoking has been the leading cause of preventable death. The prevalence of youth smoking is high, although some resources have been dedicated to this problem and the variety of interventions that have been tried to prevent smoking is a big concern from a public health perspective. As there are numerous health benefits of smoking cessation, most individuals who smoke express a desire to quit smoking. Studies show that the majority of smokers in the United States and the United Kingdom report that they want to stop or intend to quit smoking at some point in life.

In India, tobacco's associated mortality is the highest in the world, an estimated 700,000 annual deaths attributable to tobacco use Murthy [3]. Whereas, the lowest smoking rates for men can be found in Nigeria, Barbuda, and Antigua. For women, smoking rates are lowest in Eritrea, Cameroon, and Morocco (UW TODAY, 2014). A multitude of non-pharmacological and pharmacological interventions now exist to aid smokers in cessation. The financial burden imposed by cigarette smoking is enormous. Smokingrelated illness in the United States costs $\$ 96$ billion each year in medical expenses and $\$ 97$ billion in lost productivity due to premature mortality. Cigarette industries are spending billions of dollars on advertising tobacco products, attracting specifically adolescents and young adults who fuel the existing burden. The primary cause of chronic obstructive pulmonary disease (COPD) and lung cancer in adults has been cigarette smoking. There is an association between smoking and periodontal disease in children and adolescents. Smoking is responsible for $87 \%$ of the lung cancer deaths in the United States. It is responsible for $30 \%$ of all cancer deaths universally. Cigarette smokers have a lower level of lung function than those persons who have never smoked. Smoking hurts young people's physical fitness regarding both performance and endurance, even among young people trained in competitive running. On average, a person smoking a pack or more of cigarettes per day lives seven years less than the person who never smoked (Department of Health \& CDC, 2008). In 2007, 1,800 Hispanic women and almost 3,000 Hispanic men died of lung cancer. Cigarette smokers are also known to possess a greater risk than nonsmokers for heart attack (in the same year, about 3,000 Hispanic women and nearly 3,800 men died from heart attack.
Smokers have a $70 \%$ greater chance of dying from coronary heart disease than non-smokers (Department of Health \& CDC, 2011).

Overall, lung cancer is known to be the leading cause of cancer deaths among African Americans. Multiple factors are associated with tobacco use such as social, physical and environmental. Young people are more likely to use tobacco if their peers use tobacco. Perceived smoking is acceptable or normative among their peers. They expect positive outcomes from smoking, such as surviving with stress, anxiety, and depression. Parental and sibling smoking may also promote smoking among children and youth in a household where perceived parental approval plays a significant role in adolescent smoking. In Hispanic and Asian communities, families live intimately with each other. Parents have control over their children and watch their activities, and vice versa offspring also respect parents and elders. Hispanic youth are more likely than other young people to be protected from second-hand smoke by smoking bans at home. Seventy-one percent of Hispanic households do not allow smoking in their homes. Parenteral perceived disapproval of smoking is a protective factor against adolescent smoking McCausland [4]. Other factors like low socioeconomic status, lack of parental support or involvement, accessibility, availability, low level of academic achievement, low self-image and aggressive behavior have been associated with youth smoking Miller [5]. Peer pressure is a significant factor in their decisionmaking process. There are many studies showing that the influence of peers is especially powerful in determining when and how young people first try a cigarette. Even if someone thinks that their child is too smart, all children and adolescents are vulnerable either for negative or positive influence. Kids feel that they are pulled in two directions-on the one hand they do not want to use tobacco but the other side they afraid of losing friends. The smoking rate among children and young adults who have three or more friends who smoke are ten times higher than those who report that none of their friends' smoke Nicotine \& Tobacco Research [6].

According to a study concerning accessibility of cigarettes, it is seen that among the 12.9 percent of students nationwide who tried to buy cigarettes 30 days before the study, 48.5 percent them were not asked to show proof of age. The prevalence of students, not having been ID'd to show evidence of age was higher among ninth graders at $70.4 \%$ than tenth graders at $55.6 \%$, eleventh graders at $59.2 \%$, and least for twelfth graders at $32.7 \%$. For females, it was higher among eleventh graders at $57.7 \%$ compared to twelfth grader females at $29.3 \%$. Among males, ninth-graders were at $65.7 \%$, tenth graders were at $55.6 \%$, eleventh graders were at $59.6 \%$ and finally twelfth graders at $34.9 \%$. Illiteracy is another factor in youth smoking. According to the US Census Bureau report from 2007, $61 \%$ of Hispanics in comparison to $85 \%$ of non-Hispanics have a high school diploma. While only $12.5 \%$ of Hispanics compared to $30.5 \%$ of non-Hispanic, have a bachelor's degree (NSDUH 2010) [7]. Currently, there is an increasing trend of smoking prevalence among 
young women, low socio-economic, racial/ethnic minorities, and vulnerable populations such as the LGBT community (lesbian, gay bisexual, and transgendered) (USDHS, 2004). As regards quitting smoking, a study shows that Hispanic smokers are less likely than white smokers to be prescribed or to attempt quitting (CDC, 2016) (Table 1, 2).

Table 1: Countries that had the highest and lowest smoking prevalence for men in 2012.

\begin{tabular}{|c|c|}
\hline Highest & Lowest \\
\hline Timor-Leste $61.1 \%$ & Antigua and Barbuda $5 \%$ \\
\hline Indonesia $57 \%$ & Sao Tome and Principe $7 \%$ \\
\hline Kiribati $54.4 \%$ & Nigeria $7.5 \%$ \\
\hline Armenia $51.7 \%$ & Ethiopia $7.7 \%$ \\
\hline Papua New Guinea $51.4 \%$ & Ghana $8.2 \%$ \\
\hline Laos $51.3 \%$ & Sudan $8.2 \%$ \\
\hline Russia $51 \%$ & Dominica $8.4 \%$ \\
\hline Cyprus $48 \%$ & Niger $8.8 \%$ \\
\hline Macedonia $46.5 \%$ & Suriname $9.8 \%$ \\
\hline Tonga $46.4 \%$ & Ecuador $10.3 \%$ \\
\hline
\end{tabular}

Table 2: Countries that had the highest and lowest smoking prevalence for women in 2012.

\begin{tabular}{|c|c|}
\hline Highest & Lowest \\
\hline Greece $34.7 \%$ & Eritrea $0.6 \%$ \\
\hline Bulgaria $31.5 \%$ & Cameroon $0.6 \%$ \\
\hline Kiribati $31.3 \%$ & Morocco $0.7 \%$ \\
\hline Austria $28.3 \%$ & Gambia $0.8 \%$ \\
\hline France $27.7 \%$ & Libya $0.9 \%$ \\
\hline Macedonia $26.7 \%$ & Oman $0.9 \%$ \\
\hline Belgium $26.1 \%$ & Algeria $0.9 \%$ \\
\hline Chile $26 \%$ & Azerbaijan $0.9 \%$ \\
\hline Hungary $25.8 \%$ & Ethiopia $1.0 \%$ \\
\hline Andorra $25.2 \%$ & Sudan $1.0 \%$ \\
\hline
\end{tabular}

\section{Health impact}

Secondhand smoke exposure puts family members of smokers at an increased risk. The following table illustrates the various health impacts in children and adults:

Other benefits of quitting smoking are reduced chances of impotence, having difficulty getting pregnant, having premature births, babies with low birth weight and miscarriage. In children, the risk factors of many second hand smoking such as asthma and other respiratory diseases decrease Stead [8]. After quitting smoking, there are numerous physical and emotional effects the body experiences. These effects consist of are both short-term and long-term benefits. The short term benefits, which can commence as soon as 20 minutes past quitting, include heart rate and blood pressure decrease. Carbon monoxide level drops to normal after 12 hours. There is an improvement in blood circulation and lung function after two to twelve weeks of quitting. Shortness of breath and coughing decrease after one to nine months of stopping. Subsequently, two to three weeks following cessation, several regenerative processes begin to take place in the body. The long-term benefits of quitting reduce the risk of coronary heart disease after one year to one and a half. Five years past quitting, the probability of stroke is reduced to that of a nonsmoker. The potential for lung cancer, cancer of mouth, throat, esophagus, bladder, cervix and pancreas reduces to about half of that for a smoker. Within 15 years of cessation, almost all of the recuperative processes are completed. The risk of heart disease is no greater than someone who has never smoked a cigarette CDC [9]. The advantages of quitting smoking compared to those who continued to smoke are huge. Life expectancy is increased compared to those who continued to smoke. The probability of suffering from another heart attack is reduced by $50 \%$ for people who quit smoking after having a heart attack or following the onset of life-threatening disease (Table 3).

Table 3: WHO, 2011.

\begin{tabular}{|c|c|}
\hline Diseases in children & Diseases in Adults \\
\hline Sudden infant death syndrome & Coronary heart disease \\
\hline Acute respiratory illnesses & Nasal irritation \\
\hline Middle ear disease & Lung cancer \\
\hline Chronic respiratory symptoms & $\begin{array}{c}\text { Reproductive effects in women } \\
\text { (low birth weight) }\end{array}$ \\
\hline
\end{tabular}

\section{Dependence and Relapse}

The addictive effect of nicotine once smoked, makes hard to quit smoking. Early initiation increases the likely-hood of habituation, and continuous tobacco smoking eventually ends up in addiction. People who begin to smoke at a very young age are more likely to develop severe levels of smoking than those who start a later age. Tobacco addictions should be treated as a chronic disease with a constant risk of relapse Fiore [10]. Based on literature review, many studies have proved that tobacco is apparently more addictive than any other substance abuse. According to one study high rates of relapse among smoking quitters occurs due to the addiction potential of tobacco. It is reported that brief counseling has resulted in a quit rate of $55 \%$ the relapse rate among quitters was $23 \%$ Warner [11]. The current improved knowledge of the neurobiology of nicotine addiction has significant implications for the management of its dependency Joy [12].

\section{Challenges for quitting}

There are many challenges and barriers to quitting. There are three critical challenges that one should be acquainted with before planning to assist smokers to quit or attempt to quit. All people do not have the same reasons why they smoke and why they could not quit. The reasons have been classified into three categories. Physiological addiction; behavioral and environmental social; emotional or psychological connections WHO [14]. 


\section{Smoking Cessation, Smoking Prevention and Methods to Quit}

The Treating Tobacco Use and Dependence-Clinical Practice Guideline, issued by the United States Department of Health and Human Services, recommends the 5A's and 5 R's approach that should be addressed in a motivational counseling intervention to help those who are not ready to quit (HHS, 2012). The below figure illustrates the motivational counseling interventions:

There are seven first-line medications available that are known to increase long-term smoking abstinence: Nicotine inhaler, Nicotine gum, Bupropion SR Nicotine lozenge, Nicotine patch, Nicotine nasal spray, and Varenicline. Current information on adolescence tobacco use prevention has proposed that macro-level approaches can be effective in reducing the prevalence of tobacco use among adolescents. The stronger tobacco control policy that increased tobacco taxation and counter-marketing campaigns has all proven to be successful strategies for reducing youth tobacco use Backinger [14]. The use of counseling and pharmacotherapy together has been reported as the most effective strategy to achieve tobacco abstinence. The time spent on counseling is very effective since it has got a significant association between the time devoted to counseling a person quitting smoking and their chances of quitting. According to WHO guidelines, more than one type of pharmacotherapy should be offered in combination, if appropriate, for a prolonged period.

After identifying and understanding different sub-groups, various communication strategies should be developed for specific focus groups that enhance the impact of health information. The Community Preventive Services recommends the use of "massreach health communication interventions" e.g. television and radio broadcasts, newspapers, billboards, built on solid evidence for their advantageousness in preventing or reducing cigarette smoking and increasing use of cessation services like quit lines. Regarding the use of media, studies suggest that the success of different types of smoking cessation messages may vary by socioeconomic status, predominantly income and education status. Cessation programs must be custom-made to focus on the envisioned audience rather than just providing information Strickland [15] (Table 3).

\section{Nicotine replacement therapy}

Among the currently available smoking-cessation treatments, including nicotine replacement therapy (NRT), bupropion and varenicline are well-known pharmacological interventions to raise the chances of quitting tobacco smoking, mainly when combined with health education and counseling programs. Various studies have shown that tobacco cessation assistance provided by health professionals (physicians, nurses, dentists, pharmacists and other health care workers) enhances the quit rate among their patients Gorin [16]. Almost all forms of NRT gum, transversal patches, nasal sprays, inhalers and sublingual tablets can help persons who make a quit attempt and increases their chance of successfully quitting smoking by $50 \%$ to $70 \%$ irrespective of any setting. The purpose of NRT is to briefly replace considerable nicotine from cigarettes and to decrease the stimulus to smoke and avoid nicotine withdrawal symptoms consequently to ease the transition from smoking to complete abstinence.

\section{Quit-lines}

Quit-line is a tobacco cessation program which is a phone based service that helps tobacco users quit smoking. Today, residents of all 50 states in U.S. and Canada, have access to quit lines services. In the recent years, Quit-lines have been able to become a critical part of the tobacco control efforts that are ongoing in the United States. The universal access, demonstrated efficacy and the convenience of remote counseling via telephone have all led to the quick and widespread adoption of Quit lines in the North American region Cummins [17]. Currently over 53 countries have at least one national toll-free quit line with a person available to provide quit line cessation services, with access to its population. All the 50 states of USA and Canada are having multiple quit lines operated by Federal government, state government and non-governmental organizations. Out of 53 countries, 32 (60\%) of them are wealthy countries and four countries (8\%) are of low income and 17 of them are middle-income countries which made up only $18 \%$ of all middleincome countries in the world, have at least one national toll-free quit line. There is the noticeable difference in reach as well as type, quality, quantity, volume and of services provided by different quit lines. The counselors and supervisors working in quit lines are well trained by the psychiatrists for operational purpose of smoking cessation assistance. Quit-lines are established in collaboration with health care system, health care providers, nongovernmental organizations, and governments both local and national. Among the primary methods used by countries to promote quit line services are media advertisements (newspapers, television, radio or flyers). Some countries, including Brazil, New Zealand, South Africa, and all the European Union (EU), have printed the quit line number on cigarette packets together with health warnings. In spite of their widespread presence, information including international data on how Quit-lines services operate in practice and their outcome is not readily available Gollust.

\section{Complementary and alternative medicine}

Very few studies have been confirmed that the complementary and alternative medicine (CAM) for tobacco cessation, like, yoga, hypnosis, herbal products, acupuncture, relaxation, and massage therapy have been tried and were successful. However, use of complementary and alternative medicine treatments and a higher level of education were significantly associated. Yoga and mindfulness meditation as promising complementary therapies for treating and preventing addictive behaviors. The hypothetical models propose that the skills, perceptions, and self-awareness adapted through the practice of yoga and mindfulness can target 
multiple psychological, physiological, neural, and behavioral processes that maybe associated with relapse due to addiction.

\section{Electronic cigarettes:}

Also, electronic cigarettes are becoming popular and being debated concerning their role in smoking cessation. The electronic cigarettes are similarly known as e-cigarette, which is electronic nicotine delivery system a mechanical device designed to mimic regular cigarettes, looks conventional alike cigarette, and delivers nicotine through inhaling vapors without burning tobacco. These devices are supposed to deliver nicotine without any toxins considered to be a safer alternative to regular tobacco cigarettes. However, there are no sufficient studies to determine the vapors generates from e-cigarettes don't contain any toxic substances harmful to health in contrast to the natural tobacco smoking which has been proved to be carcinogenic. These electronic devices sold as a tobacco delivery device needs to be regulated. Currently, there are no uniform regulations, either no regulations or at some places complete ban on sale. Countries like Canada, Mexico, Israel, Brazil, Hong Kong, Panama, Singapore and the United Arab Emirates have completely banned e-cigarettes. Subsequently, more practical approaches are needed to reduce the burden of cigarette smoking.
E-cigarettes were used much by former smokers to avoid relapse or as an aid to cut down or quit smoking as the second option to nicotine replacement medications. Based one-cigarette literature review, it was found that electronic devices sold as a nicotine delivery device, need further research to gather scientific evidence of their safety, efficacy of device in delivering nicotine and other substances, patterns of use, effectiveness for smoking cessation or quitting, prevention of relapse, and issues associated regulations with the use of e-cigarettes. Many studies have shown that smoking e-cigarette is harmless compared to smoking traditional cigarettes. Most of the devices contain nicotine and inhaling their vapors exposes users to toxic substances, including lead, cadmium, and nickel, heavy metals that linked with significant health problems Grana.

The electronic cigarette which resembles a conventional cigarette is a battery-operated electronic device that is designed to vaporize a liquid solution. The solution is known to contain propylene glycol and or vegetable glycerin in which nicotine or other fragrances may be dissolved. During puffing activates the lithium-ion rechargeable battery that is designed to vaporize nicotine to be inhaled. The modern e-cigarette was invented in the year 2003 by a Chinese scientist Hon Like (Figure1, 2).
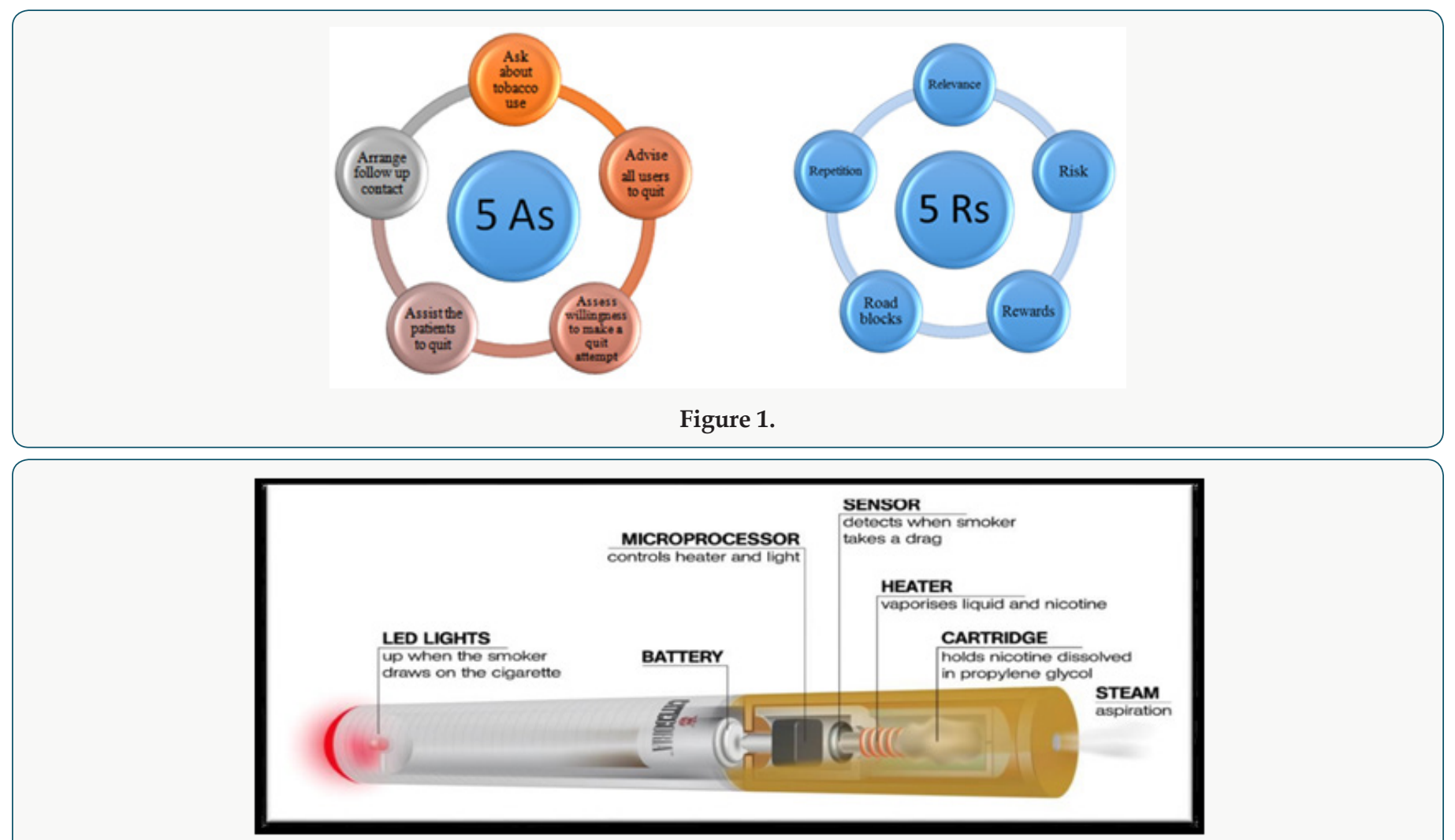

Figure 2.

Even though e-cigarette bears a resemblance exactly as the traditional conventional tobacco cigarettes has a perceptible sensation. An e-cigarette consists of a plastic tube, electronic heating element, and liquid nicotine cartridge. The conventional cigarette is soft and light in weight whereas e-cigarette is hard and heavy to feel. The e-cigarette is designed to mimic conventional cigarette provide a flavor and physical sensation like that of tobacco smoke during inhalation, but no smoke is involved in maneuvering. 
During the inhalation process in e-cigarette device, an electronic sensor senses airflow and automatically activates the heating element that heats the liquid in the cartridge which vaporizes. Also at the same time during puffs, the electronic sensor lights up a LED indicator. The cartridges may be containing nicotine suspended in propylene glycol, glycerol plus water and sometimes contains flavors of different fruits and mint or without nicotine. The nicotine vapors absorb through the mucous membrane of mouth may even enter into the blood stream, but with low concentration comparing to conventional tobacco cigarettes. Since e-cigarettes don't burn tobacco, may be considered a lower risk substitute for conventional paper and tobacco cigarette Eissenberg [18]. Toxic components, including low levels of carcinogens have been identified in some e-cigarette cartridges during laboratory testing Food and Drug Administration [19].

Many scientific research studies have identified hundreds of toxic chemicals used in the liquids in the canister of e-cigarettes were detected in the bloodstream of some persons which inhaled by smoking were known to cause health effects (may even cause cancer). Even persons have affected second-hand smoke from e-cigarette have detected toxins in the blood stream. The following chemicals are identified in e-cigarettes: Nicotine, butanone, Formaldehyde, Acetaldehyde, Acetic Acid, Acetone, Acrolein, Aluminum, Barium Benzene, Butyl hydroxyl toluene, Cadmium, Chromium, Copper Croton Aldehyde Diethylene Glycol, Glyoxal Iron Isoprene, Lead, Limonene m, p-Xylene, Magnesium, Manganese, Nickel, N-Nitrosonornicotine, Methyl benzaldehyde, Phenol, Polycyclic Aromatic Hydrocarbons, Potassium Propanol, Propylene Glycol, Sulfur, Tin, Toluene, Vale Aldehyde, Zinc Zirconium.

There are numerous unreciprocated questions about their comprehensive influence. For example; are e-cigarette used by young new non-smokers; would e-cigarettes be a gateway to tobacco use or nicotine dependency; is there any tendency for addiction to e-cigarettes or could its use in public places challenge smoke-free laws. The nicotine and other chemicals found in e-cigarettes might harm brain development in young persons and younger persons who start smoking are more likely to develop a habit and are more prone to addiction. Young persons who have never smoked or never tried smoking, when starts to use e-cigarette might get an addiction to nicotine and decide to switch to regular cigarettes is the biggest worry and public health concern, if the government does not ban e-cigarette sale to underage (Jean-François Etter, 2011).

\section{Smoking cessation policies and interventions}

Smoking cessation is vital to any tobacco control program. It is also one of the important modules of a widespread tobacco policy that strongly contributes to decreasing the smoking prevalence and thereby reduces tobacco-related morbidity and mortality. Numerous policies influence smokers' inspiration to quit smoking. The tobacco control measures such as increased taxation on tobacco and tobacco products, ban on advertising and promotion by global communications media, smoke-free areas and educational campaigns increase smokers' motivation to stop. These policies also help in creating a climate that makes it easier for former smokers to remain abstained World Health Organization [20]. An international body of research indicates smoking cessation policies and interventions are cost-effective that include two comprehensive types of activities:

a) Mass population policies and actions aimed to motivate smokers to quit smoking, such as higher prices through taxation, restrictions on smoking in public places and mass media educational campaigns.

b) 2) Policies and activities designed to help dependent smokers who are already motivated to quit Fronczak [21].

In May 2010, a committee of 20 experts from 12 countries on tobacco control, economics, epidemiology, and public health policy met at the International Agency for Research on Cancer Frank [22]. They discussed the series of evidence gathered after conducting studies on the tobacco pricing and tax related lobbying; tax, price and collective demand for tobacco; tax, price and adult tobacco use, use among adolescents and among poor; and impact of tobacco taxation on health. All the studies were conducted in both the developed and underdeveloped countries including high, medium and low income. From eighteen total studies, twelve study's conclusions were showing strength of the effectiveness on tax reduction and price increase. A small number of high-income group countries report that higher prices increased smoking cessation rate. Studies from countries of low, medium and high income report that smoking among young people decreases as price increases. After consensus, the expert scientists' committee concluded that there is sufficient evidence of effectiveness of increased tobacco excise taxes and prices in reducing the prevalence of tobacco use and improvement of public health.

Uruguay, a middle-income country in South America, implemented a comprehensive continued program of multiple tobacco control procedures consisting of a ban on publicity and promotion. Additionally, the ban on smoking in enclosed public spaces and workplaces, the policy for healthcare providers to treat nicotine dependence. Furthermore, a rule, that signs with warnings cover eighty percent of the front and back of every cigarette pack in addition to the ban on using misleading terms such as light and mild, besides a considerable increase in tobacco taxes. The results reported over during six years' period from 2005 to 2011 was about a 23\% decrease in tobacco use Abascal [23]. According to a Global Youth Survey (GYT) from Bangladesh, a low-income country in Asia, report between 2007 and 2013, the use of tobacco and its products has not decreased. The rationale being no good smoking cessation programs and lack of resources and insufficient policies on tobacco control. This is despite many students (59.9\%) expressing the desire to quit smoking if they have proper guidance and tools World Health Organization [24]. 
Brazil, an upper middle-income country, being a third largest tobacco producing country in the world, has a comprehensive tobacco control policy including restrictions on publicity, ban on smoking in indoor public areas, mandatory pictorial warning labels on cigarette packs and total ban on menthol cigarettes, increase tax and pricing policies. One study showed that increase taxes and price rise have great potential to stimulate cessation and reduces prevalence among the vulnerable population Gigliotti [25-75].

\section{Conclusions}

This review suggests the trends of smoking habits and smoking cessation intervention strategies differ from region to region when viewed from an international perspective. This highlights the necessity for the improvement of new methods that prevent people from starting to smoke, motivate to quit smoking and sustain longterm cessation. Further, we suggest exploring how to change more smokers to try quit and to choose the most appropriate evidencebased practical approach and to try more frequently. If appropriate and applicable, poly pharmacotherapy should be offered for a prolonged period since relapse is more common. Cessation programs must be custom-made to focus on the envisioned audience rather than just providing information. It is observed by many that e-cigarette to be harmless than traditional cigarettes, still a lot of the devices contain nicotine and inhaling their vapors exposes users to toxic substances, including lead, cadmium, and nickel, heavy metals that linked with significant health problems (Grana, 2014).In developing countries due to lack of infrastructure, and funds are the major drawback towards the success of smoking control and smoking cessation, rich countries should extend help in the implementation of intervention programs. Additionally, countries can also contribute by strictly implementing taxation on cigarettes and also increase the price of tobacco and tobacco products in general. Future research should be directed to assess whether increasing the number of quitting attempts would positively impact smoking cessation.

\section{References}

1. Hyland A, Borland R, Li Q, Yong HH, McNeill A, (2006) et al. Individuallevel predictors of cessation behaviors among participants in the international tobacco control (ITC) four country survey. Tob Control 15(suppl 3): iii83-iii94.

2. National Survey on Drug Use and Health (2014) Tobacco/Nicotine.

3. Murthy P, Saddichha S (2010) Tobacco services in India: Recent developments and the need for expansion. Indian J Cancer 47 (Suppl 1): 69-74.

4. Mc Causland K, Thomas K, Watson-Stryker E, Xiao J, Green, et al. (2005) Legacy First Look Report 14. Secondhand Smoke: Youth Exposure and Adult Attitudes. Washington DC: American Legacy Foundation.

5. Miller G, Manoj Sharma, FAAHB David Brown, Ed. D, MA Mohammad Shahbazi.

6. Nicotine and Tobacco Research. (2009) 11(2): 203-210.

7. Results from the 2010 National Survey on Drug Use and Health: Summary of National Findings". Samhsa gov Np (2016).
8. Lancaster T, Stead L, Silagy C, Sowden A (2000) Effectiveness of interventions to help people stop smoking: Findings from the Cochrane Library. BMJ 321(7257): 355-358.

9. U.S. Department of Health and Human Services. The Health Consequences of Smoking-50 Years of Progress: A Report of the Surgeon General. Atlanta: US Department of Health and Human Services, Centers for Disease Control and Prevention, National Center for Chronic Disease Prevention and Health Promotion, Office on Smoking and Health (2014).

10. Fiore MC, Jaen CR, Baker TB, Bailey WC, Benowitz N, et al. (2008) Treating tobacco use and dependence: 2008 Update. Rockville (MD): US Department of Health and Human Services.

11. Gollust SE, Schroeder SA, Warner KE (2008) Helping smokers quit: understanding the barriers to utilization of smoking cessation services. Milbank Quarterly 86(4): 601-627.

12. National Academy of Sciences. Marijuana and Medicine: Assessing the Science Base. In: Joy JE, Watson SJ, Benson JA, editors. Institute of Medicine (2012).

13. WHO Report on the Global Tobacco Epidemic, 2008: the MPOWER Package? Geneva, World Health Organization.

14. Backinger CL, Fagan P, Matthews E, Grana R (2003) Adolescent and young adult tobacco prevention and cessation: current status and future directions. Tobacco Control 14: iv46-iv53.

15. Strickland JR, Smock N, Casey C, Poor T, Kreuter MW, (2015) Development of targeted messages to promote smoking cessation among construction trade workers. Health education research 30(1): 107-120.

16. Gorin SS, Heck JE (2004) Meta-analysis of the efficacy of tobacco counseling by health care providers. Cancer Epidemiol Biomarkers Prev 13(12): 2012-1022.

17. Cummins SE, Bailey L, Campbell S, Koon-Kirby C, Zhu SH (2007) Tobacco cessation quit lines in North America: a descriptive study. Tobacco Control 16(Suppl 1): i9-i15.

18. Eissenberg T (2010) Electronic nicotine delivery devices: ineffective nicotine delivery and craving suppression after acute administration. Tob Control 19(1): 87-88.

19. Summary of Results: Laboratory Analysis of Electronic Cigarettes Conducted by FDA, US: Food and Drug Administration (FDA) (2009).

20. World Health Organization (2004) WHO European strategy for smoking cessation policy.

21. Fronczak A, Polanska K, Usidame B, Kaleta D (2012) Comprehensive tobacco control measures-the overview of the strategies recommended by WHO. Central European journal of public health 20(1): 81-86.

22. Frank Chaloupka, Kurt Straif, Maria E Leon (2010) 20(3): 235.

23. Abascal W, Esteves E, Goja B, Mora FG, Lorenzo A, (2012) Tobacco control campaign in Uruguay: a population-based trend analysis. The Lancet 380(9853): 1575-1582.

24. World Health Organization (2015) Global Youth Tobacco Survey (GYTS), Bangladesh Report.

25. Gigliotti A, Figueiredo VC, Madruga CS, Marques AC, Pinsky I, et al. (2014) How smokers may react to cigarette taxes and price increases in Brazil: data from a national survey. BMC public health 14: 327.

26. Abdullah ASM, Husten CG (2004) Promotion of smoking cessation in developing countries: a framework for urgent public health interventions. Thorax 59(7): 623-630.

27. American-Legacy-Foundation. Electronic Cigarette ('e-cigarette') Fact Sheet. American Legacy Foundation (2009-11). 
28. African Americans and Tobacco Use (2016).

29. Borland R, Borland R, Segan CJ, Borland R, Segan CJ (2006) The potential of Quit lines to increase smoking cessation. Drug and alcohol review 25(1): 73-78.

30. Bullen C, McRobie H, Thornley S, Glover M, Lin R, (2010) Effect of an electronic nicotine delivery device (e cigarette) on the desire to smoke and withdrawal, user preferences and nicotine delivery: randomized cross-over trial. Tobacco control 19(2): 98-103.

31. Caponnetto P, Auditore R, Russo C, Cappello GC, Polosa R (2013) Impact of an electronic cigarette on smoking reduction and cessation in schizophrenic smokers: a prospective 12-month pilot study. International journal of environmental research and public health 10(2): 446-461.

32. Morbidity and mortality weekly report 61(31): 581.

33. Caponnetto P, Campagna D, Cibella F, Morjaria JB, Caruso M, et al. (2013) Efficiency and Safety of an eLectronic cigarette (ECLAT) as Tobacco Cigarettes Substitute: A Prospective 12-Month Randomized Control Design Study. PLOS ONE 8(6): e66317.

34. Doll R, Peto R, Boreham J, Suther land I (2004) Mortality in relation to smoking: 50 years' observations on male British doctors. BMJ 328(7455): 1519-1527.

35. Durkin SJ, Biener L, Wakefield MA (2009) Effects of different types of antismoking ads on reducing disparities in smoking cessation among socioeconomic subgroups. Amj Public Health 99(12): 2217-2223.

36. Despite declines in smoking rates, number of smokers and cigarettes rises.

37. Etter JF, Bullen C (2011) Electronic cigarette: users profile, utilization, satisfaction, and perceived efficacy. Addiction 106(11): 2017-2028.

38. Fiore MC, Bailey WC, Cohen SJ (2010) Treating tobacco use and dependence: Clinical Practice Guideline, Rockville, MD: US Department of Health and Human Services 2000.

39. Fiore MC (2000) Treating Tobacco Use and Dependence. Clinical Practice Guideline. Rockville, MD, US Department of Health and Human Services. Public Health Service.

40. Five Major Steps to Intervention (The “5 A's”) (2012).

41. Grana R, Benowitz N, Glantz SA (2014) E-cigarettes a scientific review. Circulation 129(19): 1972-1986.

42. Genco RJ (1996) Current View of Risk Factors for Periodontal Diseases*. Journal of periodontology 67(10s): 1041-1049.

43. Grana R, Benowitz N, Glantz SA (2014) E-cigarettes a scientific review. Circulation 129(19): 1972-1986.

44. Kim HJ, Shin HS (2013) Determination of tobacco-specific nitrosamines in replacement liquids of electronic cigarettes by liquid chromatographytandem mass spectrometry. Journal of Chromatography A 1291: 48-55.

45. Jha P, Chaloupka FJ (1999) Curbing the epidemic: governments and the economics of tobacco control. World Bank Publications.

46. Lichtenstein E, Zhu SH, Tedeschi GJ (2010) Smoking cessation quit lines: An under recognized intervention success story. American Psychologist 65(4): 252-261.

47. Lourdes Baezconde-Garbanati, Aida McCammon, Jean A Leroux Guillén, BGS. This report is available in Spanish, translated by Lizbeth Perez.

48. MMWR Morbidity and Mortality Weekly Report 61(31): 581-585.

49. Mackay J, Eriksen M (2002) The tobacco atlas. Geneva: World Health Organization.

50. New e-cig risk assessment uses the wrong standard (2013).
51. National Center for Chronic Disease Prevention and Health Promotion, Office on Smoking and Health (2004).

52. Nishori R, Weaver R What are the physical, social and financial effects of smoking?

53. Niederdeppe J, Farrelly MC, Nonnemaker J (2011) Socio economic variation in recall and perceived effectiveness of campaign advertisements to promote smoking cessation. Soc Sci Med 72(5): 773 780 .

54. Niederdeppe J, Fiore MC, Baker TB (2008) Smoking cessation media campaigns and their effectiveness among socioeconomically advantaged and disadvantaged populations. Amj Public Health 98(5): 916-924.

55. Odh ohio gov Np (2016).

56. Pradeep Kumar AS, Thankappan KR, Nichter M (2008) Smoking among tuberculosis patients in Kerala, India: Proactive cessation efforts are urgently needed. Int J Tuberc Lung Dis 10(12): 1139-1145.

57. Patients Not Ready to Make a Quit Attempt Now (The “5 R's”). (2012).

58. Raub JA (2002) Psycho physiologic effects of Hatha Yoga on musculoskeletal and cardiopulmonary function: a literature review. The Journal of Alternative \& Complementary Medicine 8(6): 797-812.

59. Richardson A, Xiao H, Vallone DM (2012) Primary and dual users of cigars and cigarettes: profiles, tobacco use patterns and relevance to policy. Nicotine \& Tobacco Research 14(8): 927-932.

60. Stead LF, Perera R, Bullen C, Mant D, Hartmann-Boyce J, et al. (2012) Nicotine replacement therapy for smoking cessation. Cochrane Database of Systematic Reviews 11.

61. Stephenson C, Stephenson M (2011) Hearing loss prevention for carpenters: part 1-using health communication and health promotion models to develop training that works. Noise Health 13(51): 113-122.

62. Stephenson C, Stephenson M, Graydon P (2011) Hearing loss prevention for carpenters: Part 2- Demonstration projects using individualized and group training. Noise Health 13(51): 122-131.

63. The tobacco use and dependence Clinical Practice Guideline Panel, Staff and Consortium representatives. A Clinical Practice Guideline for treating tobacco use and dependence, A US Public Health Service report. JAMA (2000) 283(24): 3244-3254.

64. Torre LA, Bray F, Siegel RL, Ferlay J, Lortet-Tieulent, et al. (2015) Global cancer statistics, 2012. CA: a cancer journal for clinicians 65(2): 87-108.

65. US Department of Health and Human Services 2004, The Health Consequences of Smoking: A Report of the Surgeon General, US Department of Health and Human Services, Centers for Disease Control and Prevention, National Center for Chronic Disease Prevention and Health Promotion, Office on Smoking and Health.

66. World Health Organization (2011) WHO report on the global tobacco epidemic, 2011: Warning about the dangers of tobacco: Executive summary.

67. WHO (2016) Fact sheet about health benefits of smoking cessation.

68. WHO (2008) Report on the Global Tobacco Epidemic. The MPOWER package.

69. West R (2008) Smoking and smoking cessation in England.

70. World Health Organization (2007) A WHO/The Union monograph on TB and tobacco control: joining efforts to control two related global epidemics. Geneva: World Health Organization.

71. West R, McNeill A, Raw M (2000) Smoking cessation guidelines for health professionals: An update. Thorax 55(12): 987-999. 
72. WHO report on the global tobacco epidemic, 2011: warning about the dangers of tobacco? Geneva, World Health Organization.

73. WHO report on the global tobacco epidemic, 2009: Implementing smoke-free environments. Geneva, World Health Organization.
74. World Health Organization (2015) Global Youth Tobacco Survey (GYTS), Bangladesh Report.

75. Warner KE, Mackay JL (2008) Smoking cessation treatment in a public health context. Lancet 371: 1976-1978.

\section{(c) (i) \\ This work is licensed under Creative Commons Attribution 4.0 License}

To Submit Your Article Click Here:

Submit Article
DOI: 10.32474/TRSD.2018.01.000103

\section{Theranostics of Respiratory \& Skin Diseases}

Assets of Publishing with us
- Global archiving of articles
- Immediate, unrestricted online access

